\title{
Corrigendum: Unifying Speed-Accuracy Trade-Off and Cost-Benefit Trade-Off in Human Reaching Movements
}

\author{
Luka Peternel ${ }^{1,2}$, Olivier Sigaud ${ }^{3 *}$ and Jan Babič ${ }^{3 *}$ \\ ${ }^{1}$ HRII Lab, Advanced Robotics, Istituto Italiano di Technologia, Genoa, Italy, ${ }^{2}$ Department for Automation, Biocybernetics and \\ Robotics, Jožef Stefan Institute, Ljubljana, Slovenia, ${ }^{3}$ Sorbonne Universités, UPMC Univ Paris 06, CNRS UMR 7222, Institut \\ des Systèmes Intelligents et de Robotique, Paris, France
}

Keywords: expected utility, hit dispersion, cost-benefit, speed-accuracy, arm reaching

\section{A corrigendum on}

Unifying Speed-Accuracy Trade-Off and Cost-Benefit Trade-Off in Human Reaching Movements

by Peternel, L., Sigaud, O., and Babič, J. (2017). Front. Hum. Neurosci. 11:615. doi: $10.3389 /$ fnhum.2017.00615

There was a confusing notation of expectation in the Equations (2) and (4) in the original article. The original notation $\mathbb{E}(\boldsymbol{s}, \boldsymbol{u})(\ldots)$ could be misinterpreted as expectation of variables $\boldsymbol{s}$ and $\boldsymbol{u}$ themselves multiplied by the integral part inside (...), while in fact the notation represents the expectation of integral part inside the $(\ldots)$, where $(\boldsymbol{s}, \boldsymbol{u})$ only indicates that the random variables are $\boldsymbol{s}$ and $\boldsymbol{u}$. The clearer notation would be $\mathbb{E}_{\boldsymbol{s}, \boldsymbol{u}}(\ldots)$. The corrected versions of equations/text are below.

$$
J(\boldsymbol{u})=\mathbb{E}_{\boldsymbol{s}, \boldsymbol{u}}\left(\int_{0}^{\infty}\left[e^{-t / \gamma} \rho R\left(\boldsymbol{s}_{t}\right)-v L\left(\boldsymbol{u}_{t}\right)\right] d t\right),
$$

where $\mathbb{E}_{\boldsymbol{s}, \boldsymbol{u}}(\ldots)$ denotes the expectation over the random variables $\boldsymbol{s}$ and $\boldsymbol{u}$, which is the probabilityweighted average of its argument over infinitely many repetitions.

\section{OPEN ACCESS}

Edited and reviewed by: Mikhail Lebedev,

Duke University, United States

${ }^{*}$ Correspondence:

Olivier Sigaud

olivier.sigaud@upmc.fr

Jan Babic

jan.babic@ijs.si

Received: 18 January 2018 Accepted: 12 February 2018 Published: 20 February 2018

Citation:

Peternel L, Sigaud $O$ and Babič $J$

(2018) Corrigendum: Unifying

Speed-Accuracy Trade-Off and

Cost-Benefit Trade-Off in Human

Reaching Movements.

Front. Hum. Neurosci. 12:76.

doi: 10.3389/fnhum.2018.00076

$$
J(\boldsymbol{u})=\mathbb{E}_{\boldsymbol{s}, \boldsymbol{u}}\left(\int_{0}^{\infty}\left[e^{-t / \gamma} \rho R\left(\boldsymbol{s}_{t}\right)-v L\left(\boldsymbol{u}_{t}\right)\right] d t+C\left(\boldsymbol{s}_{f}\right)\right),
$$

In the original article, we forgot to include the Acknowledgments section.

\section{ACKNOWLEDGMENTS}

The authors would like to thank Gowrishankar Ganesh for his valuable feedback regarding the paper, Corentin Arnaud for his help with the code and Zrinka Potočanac for her help during the experiments.

The authors apologize for these oversights and state that they do not change the scientific conclusions in any way.

The original article has been updated.

Conflict of Interest Statement: The authors declare that the research was conducted in the absence of any commercial or financial relationships that could be construed as a potential conflict of interest.

Copyright (C) 2018 Peternel, Sigaud and Babič. This is an open-access article distributed under the terms of the Creative Commons Attribution License (CC BY). The use, distribution or reproduction in other forums is permitted, provided the original author(s) and the copyright owner are credited and that the original publication in this journal is cited, in accordance with accepted academic practice. No use, distribution or reproduction is permitted which does not comply with these terms. 